\title{
Crise econômica, pandemia e a política de transferência de renda no Brasil
}

\section{Economic crisis, the pandemic and the income redistribuition policy in Brazil}

\author{
Andréa Braz da Costa \\ Marcos A. Tavares Soares ${ }^{2}$
}

\begin{abstract}
Resumo: A discussão da renda básica, há muito presente no meio acadêmico, toma forma de um grande debate nacional e encontra espaço na formação da agenda pública como instrumento necessário no combate aos efeitos da Covid-19. O objetivo do artigo é analisar a evolução e importância das políticas de transferência de renda como instrumento de proteção social, destacando o tratamento dado a estas pelo governo brasileiro em momentos de crise, especialmente no contexto da pandemia da Covid-19 e da instituição do Auxílio Emergencial (AE). Para o desenvolvimento do artigo recorreu-se à pesquisa bibliográfica e documental (análise de lei e dados secundários do IBGE, IPEA, MC, CEF etc.) com o propósito de apresentar argumentos que fundamentam o debate acerca das políticas de proteção social. Verificou-se que a pandemia chegou ao Brasil num contexto em que o quadro social se deteriorava em função do aprofundamento da agenda liberal adotada a partir de 2015: o PIB de 2019, em valor real, é menor que o de 2014; a taxa de desemprego até fevereiro de 2020 era quase o dobro da registrada em 2014; e a pobreza se expandiu. Apesar desse quadro, nos primeiros quinze meses do governo Bolsonaro foram excluídas mais de um milhão de famílias do PBF e 25 mil beneficiários do BPC. Diante do agravamento da crise econômica provocado pela Covid-19, o Congresso Nacional aprovou o AE, que alcançou mais de 65 milhões de pessoas. Conclui-se que é necessário manter o AE e incluir boa parte dos 40 milhões de pessoas que não foram atendidas, até que seja aprovado um programa de renda mínima permanente pari passu a reformas estruturais imprescindíveis ao combate à pobreza e às desigualdades.
\end{abstract}

Palavras-chave: Auxílio Emergencial. Transferência de renda. Covid-19.

Abstract: The discussion of a minimum wage which has long been present in the academia, has now drawn attention to a nationwide debate and has found its place within the general public agenda as a suitable tool against the effects of Covid-19. This article aims to analyse the evolution and importance of income redistribution policies as an instrument to social protection, highlighting the way the brazilian government deals with it in times of crises, specially in the context of the Covid-19 pandemic and the creation of Auxilio Emergencial AE (cash-transfer program called emergency aid). For the development of the article, bibliographical and documentary research (analysis of law and secondary data from IBGE, IPEA, MC, CEF, etc.) were used in order to present arguments that support the debate on social protection policies. Its pointed out that the pandemic affected Brazil during a context where the social

${ }^{1}$ Graduada em Ciências Econômicas pela Universidade Federal da Paraíba (UFPB). Mestre em Economia Regional pela Universidade Federal de Campina Grande (UFCG). Professora Assistente na Universidade Estadual do Sudoeste da Bahia (UESB). Integrante do Núcleo de Pesquisas em Trabalho, Política e Sociedade (NETPS/UESB). E-mail: andrea.braz@uesb.edu.br.

2 Graduado em Ciências Econômicas pela Universidade Estadual de Feira de Santana (UEFS). Mestre em Economia Regional pela Universidade Federal de Campina Grande (UFCG). Professor Assistente na Universidade Estadual do Sudoeste da Bahia (UESB). Integrante do Núcleo de Pesquisas em Trabalho, Política e Sociedade (NETPS/UESB). E-mail: marcostavarespe@gmail.com 
aspects had worsen due to the strong liberal policies adopted since 2015. The GDP of 2019, in real value, is lower than the 2014; the unemployment rate until February 2020 was almost twice as recorded in 2014; and poverty has expanded. Nevertheless, in the first fifteen months of the Bolsonaro government, more than one million PBF families (social welfare program based on cash-transfer for target families) and 25,000 BPC beneficiaries (social cash-transfer program for older or those with disabilities) were excluded. The worsening situation of the economic crisis due to Covid-19 led the National Congress to approve the $\mathrm{AE}$ that eventually has reached more than 65 million people. Finally, we conclude that it is necessary to keep and expand the $\mathrm{AE}$ to the 40 million people who were not benefited until a permanent minimum wage program is approved pari passu with the structural reforms that are essential in the fight against poverty and inequality.

Keywords: Emergency Aid. Income redistribution. Covid-19.

\section{Introdução}

Eis que a discussão da renda básica, há muito presente no meio acadêmico, toma forma de um grande debate nacional e encontra espaço na formação da agenda pública como instrumento necessário ao combate aos efeitos da Covid-19. Uma discussão não só nacional, mas internacional, pois diversos países em todo o mundo estão discutindo e criando programas de apoio emergencial para pessoas vulneráveis economicamente, nesse contexto de pandemia. Países como Reino Unido, Itália, Espanha, Estados Unidos, Japão, Argentina, Chile, Colômbia, Peru, entre outros, estão criando alternativas das mais diversas características e alcances que têm como fundamento central o combate aos efeitos deletérios da Covid-19 na sociedade e na economia, advindos do necessário isolamento social.

No Brasil o Auxílio Emergencial (AE) foi aprovado no mês de abril e desde o momento em que foram iniciadas as discussões para o seu desenho, aprovação e implementação, muito debate tem sido travado sobre a sua pertinência e manutenção. E é sobre essa discussão que o artigo objetiva se debruçar. O objetivo do artigo é analisar a evolução e importância das políticas de transferência de renda como instrumento de proteção social, destacando o tratamento dado a estas pelo governo brasileiro em momentos de crise, especialmente no contexto da pandemia da Covid-19 e da instituição do Auxílio Emergencial. Para o desenvolvimento do artigo recorreu-se à pesquisa bibliográfica e documental com o fim de apresentar um conjunto de argumentos e dados que afirmam a necessidade de políticas de proteção social, bem como de políticas econômicas que priorizem o bem-estar de sua sociedade como um todo.

No Brasil, a realidade social é marcada pela pobreza e pela alta desigualdade social, isso mesmo antes da pandemia advinda do Covid-19 e que tende a piorar nessa conjuntura. De acordo com a Síntese dos Indicadores Sociais (IBGE, 2019), 25,3\% da população tinham rendimentos inferiores a $\mathrm{R} \$ 420,00$ (44\% do salário mínimo) em 2018, patamar correspondente à linha de pobreza do Banco Mundial para países do porte do Brasil, que considera como pobres os indivíduos que recebem até US\$ 5,5 por dia. Considerando os dados de 2015, esse percentual de pobres aumentou de 23,7\% para 25,3\%. Esse aumento da pobreza ocorre no período de variações negativas acumuladas do PIB (de 5,5\% entre 2014 e 2018), segundo esse mesmo estudo do IBGE.

No mercado de trabalho, entre 2015-2018, os indicadores também apontaram para a deterioração com o "[...] aumento da subutilização da força de trabalho e da elevada desocupação, [bem como] os resultados revelaram que as condições de trabalho foram desfavoráveis também para os que se 
mantiveram ocupados" (IBGE, 2019, p.16). De acordo com a PNADC (IBGE, 2020), comparando a taxa de desocupação do primeiro trimestre de 2014 com a de 2018, observa-se que esta saiu 7,2\% para 13,1\%.

Essas informações são apresentadas para fotografar de modo rápido o quadro já preocupante presente no contexto pré-pandemia no Brasil, considerando os dados disponibilizados. Ou seja, a economia brasileira adentra 2020 com uma população mais pobre, com performance econômica do PIB pífia ou nula, e mais desemprego, o que torna a nossa situação ainda mais grave diante de um desafio mundial de combate à Covid-19.

O artigo está dividido em sete seções incluindo esta introdução. Espera-se colaborar com o fortalecimento das argumentações que reforçam a mudança de rota em busca de um caminho diferente para o país - um caminho mais inclusivo. Se em momentos de crise mudanças podem acontecer, é mais que chegada a hora da implementação de políticas de transferência de renda substancial associada a mudanças estruturais.

\section{A proteção social ao longo da história e o contexto em que surgem as propostas de uma renda} básica

A discussão em torno da instituição de renda básica não é nova e encontra uma miríade de propostas e ações vigentes nos quatro cantos do mundo. Como uma discussão muito presente no mundo da política social, sua raiz é encontrada nas formas de intervenção social ao longo da história. Vários foram os momentos em que experiências foram reportadas na perspectiva de garantia de um mínimo de existência a certas categorias de pessoas (inválidos, idosos, viúvas, órfãos, indigentes, etc.), conforme aponta Silva (1997). Esse ponto de partida recai nas formas encontradas ao longo de nossa história, em que são identificados traços de formas de intervenção social entre os mais vulneráveis. Embora os estudos reportem-se ao século VII, só a partir do fim do séc. XVI, na Escócia, e no início do séc. XVII, na Inglaterra, a renda mínima passa a ter existência, mas ainda de modo limitado, esporádico além de muito específico para a realidade da época (SILVA, 1997).

Castel (1999) dedica-se a fazer o resgate, ao longo da história, de práticas sociais, de formas de intervenção social e de amparo aos mais pobres, reportando-se a práticas desde os tempos mais remotos até finais do século XX, de modo a observar as metamorfoses da questão social. $\mathrm{O}$ autor se reporta aos papéis da família, da comunidade e da igreja, e esta última por muito tempo foi a reguladora da assistência. Posteriormente, verifica-se a sistematização dessas ações de amparo social que envolviam e que são associadas ao advento da nova política social no início do século XVI. Castel (1999) destaca que essa sistematização ocorre em um contexto econômico e social desfavorável, como detalha a seguir:

[...] crises de subsistência, aumento do preço dos produtos alimentares, subemprego ligado a uma vigorosa expansão demográfica após as hecatombes devidas à peste, às reestruturações agrárias, ao crescimento anárquico das cidades. Os fatores de desagregação social, perceptíveis há pelo menos dois séculos, acentuam-se brutalmente (CASTEL, 1997, p.73).

Observa-se que é um período de mudanças que assinalam um momento de desequilíbrios sociais significativos. É nesse contexto que várias iniciativas se concretizam ao longo de séculos que marcam um 
período de transição entre feudalismo e capitalismo. Na Europa Ocidental, o amparo social se concretizou em diversas leis dos pobres. Segundo Pereira (2008, p.62-67, grifo do autor), foram criadas leis que objetivavam controlar a "[...] perambulância de pessoas em busca de melhores ocupações, ou a chamada 'vagabundagem"”; “[...] licença para mendigar em áreas designadas [...]”; a criação de "[...] Poor-houses (Casa dos Pobres), nas quais eram alojados tanto incapazes como capazes para o trabalho"3. O que se verifica, de modo geral, é a preocupação em controlar a pobreza e nunca eliminar os fatores causadores.

Para os liberais, como Thomas Malthus, Joseph Townsend e David Ricardo, entre outros (PEREIRA, 2008), a lei dos pobres, tal como estava funcionando, constituía-se em uma intervenção demasiada, pois afetava a mobilidade, oferta e preço do trabalho, era um instrumento caro, pois demandava de forma crescente um montante de recursos para financiá-la, não constituindo-se assim em modo de intervenção apropriado para o nascente capitalismo inglês. E é em linha com essa perspectiva em 1834 que a Lei dos Pobres é reformada.

Observa-se que as formas de intervenção social, especialmente as leis dos pobres na Inglaterra, continuavam a atuar, mas de modo a não atrapalhar mais o maciço emprego de trabalhadores dentro da lógica de mercado. Isso ocorre em um contexto de êxodo rural intenso dos trabalhadores para as cidades, em busca de formas de sobrevivência, marcado também pelo desenvolvimento do capitalismo que gerava muita riqueza acumulada em poucas mãos pari passu a geração e expansão da pobreza, o que gerou recorrentes agitações da classe trabalhadora. Ao mesmo tempo, constata-se o crescimento da organização desta que passa a se mobilizar em busca de melhores condições de trabalho, de remuneração e para a criação de mecanismos de proteção social de auxílio mútuo que funcionavam para a cobertura de vários riscos (velhice, invalidez, morte, doença, maternidade e acidente de trabalho) financiados pela contribuição de trabalhadores e empregadores. Esse processo iniciado no século XIX passa a caracterizar a fase inicial de um novo sistema de proteção social que apenas se consolida no século XX.

A primeira metade do século XX foi marcada pela crise de 1929, com epicentro nos EUA, e por duas Grandes Guerras Mundiais. Esses eventos tiveram implicações negativas nas economias capitalistas e revelaram a incapacidade do mercado de solucionar os problemas sociais e econômicos que se explicitavam, como o desemprego e a pobreza crescente. Ao mesmo tempo, as economias conhecidas como Socialismo real registravam baixas taxas de desemprego e de desigualdade. Diante disso, os chefes de Estado dos países capitalistas, especialmente os europeus, se viram desafiados a apresentar à sociedade um modelo de desenvolvimento que foi consolidado a partir do que ficou conhecido como Welfare State 4 .

\footnotetext{
${ }^{3}$ De acordo com Pereira (2007, p.64) em 1601 uma nova Poor Law Act instituiu grupos distintos de atendimento classificados em "[...]pobres impotentes [...], que deveriam ser alojados na Poor-houses ou Almshouses (asilos mentais); pobres capazes para o trabalbo, ou mendigos fortes, que deveriam [...] trabalhar nas [...] Workhouses; e os capazes para o trabalho, mas que se recusavam a fazêe-lo [...] encaminhados para reformatórios ou casas de correção".

${ }^{4} \mathrm{O}$ desafio de se falar em Welfare State é encontrar uma definição simples e sintética, pois no debate sobre ele há uma ampla gama de denominações e conceitos. Segundo Medeiros (2001, p.6) referindo-se a uma definição ampla destaca que Welfare State pode ser “[...] entendido como a mobilização em larga escala do aparelho de Estado em uma sociedade capitalista a fim de executar medidas orientadas diretamente ao bem-estar da população". Pereira (2008) localiza o Welfare State como um fenômeno histórico, datado no tempo e que está associado com "[...] os rumos adotados pelo sistema capitalista, que deixou de ser liberal, nos anos 1940, por uma questão de sobrevivência, para ser temporariamente regulado" (2008, p.87). A autora ainda complementa mencionando que
} 
Foi nesse contexto que as discussões acerca de renda mínima começaram a acontecer na Europa, contudo, com a expansão do emprego formal, dos direitos sociais e trabalhistas e redução da pobreza, as discussões em torno da instituição de políticas de renda mínima ficaram hibernando.

Com a crise do capitalismo na década de 1970 e a crise do Welfare State na década de 1980, o debate em torno da renda mínima ganha força e as políticas de proteção à população vulnerável se concretizam como uma das alternativas, principalmente na Europa, em face da elevação das taxas de desemprego e do empobrecimento da população. Cabe destacar que, embora programas de garantia de renda só surgissem nesse período, a ebulição das discussões nos mais diversos segmentos da sociedade começou a ocorrer após um período marcado pela crise de 1929 e pelas duas guerras mundiais. Isso só reforça o porquê de hoje se retomar o debate em torno da renda mínima. Mas, esse ponto será abordado mais à frente.

Referindo-se ao contexto da década de 1980, esse período foi marcado pela reestruturação produtiva - emergido nos países desenvolvidos e, em seguida, implantado nos países subdesenvolvidos — desencadeando um movimento de mudanças estruturais que atingiu, progressivamente, a maioria dos países, principalmente, e mais intensivamente, os países subdesenvolvidos, a exemplo dos países da América Latina, que se encontravam reféns do endividamento de suas economias, sendo levado ao seu limite. A reestruturação produtiva veio acompanhada do avanço das políticas neoliberais de Estado mínimo para o social e máximo para o capital. Os efeitos na América Latina desses dois processos, um na esfera da produção e o outro na esfera da política, guardadas as devidas especificidades de cada país, foram caracterizados como desajustes sociais, pois se constatou desmantelamento do serviço público, maior comprometimento do Estado com o rentismo, elevação dos níveis de concentração de renda, aumento do desemprego e da informalidade e o crescimento da pobreza, entre outros efeitos. É nesse contexto que a transferência de renda se apresenta como um instrumento de combate à pobreza.

\section{Dez anos de expansão das políticas de transferência de renda no Brasil (2004/2014)}

Antes de adentrar no foco da seção, cabe destacar alguns aspectos que marcam o período que antecede os anos 2000 e pautam as primeiras experiências de transferência de renda não contributiva no Brasil. Muito embora seja a partir da década de 1990 que o país fortalece ações dessa natureza, o debate acerca de programas de transferência de renda (PTR) aqui não é novo.

Os PTRs podem ser caracterizados como formas de intervenção do Estado no combate à pobreza, podendo ser universal ou focalizar a população mais vulnerável. Nesse contexto, em 1975, foi criada a Renda Mensal Vitalícia de meio salário mínimo para idosos com mais de 70 anos e pessoas portadoras de invalidez. Posteriormente na Constituição Federal (CF) de 1988 foi alterado para um benefício de um salário mínimo, tendo como beneficiários idosos com mais de 65 anos de idade e pessoas com deficiência, conhecido agora como Benefício de Prestação Continuada (BPC). Até hoje essa é a única

para além de um modelo de Estado, o Welfare State constituiu-se em um modelo de sociedade que "[...] engloba diferentes esferas (produção, distribuição e consumo) e diferentes interesses (do mercado, do Estado, dos trabalhadores, dos cidadãos em geral) [...]” (2008, p.87). 
Transferência de Renda garantida como direito na Constituição de 1988 para aqueles que se encaixam nos critérios de elegibilidade, tendo no Brasil 4.626 .888 beneficiários $^{5}$ (MINISTÉRIO..., 2020a).

É a partir da Constituição de 1988 que se estruturam institucionalmente as bases da seguridade social brasileira, assegurando status de direito social para a assistência social, fortalecendo o direito à renda mínima a pessoas que não contribuíram diretamente para o fundo público. Paradoxalmente, isso ocorreu no Brasil em um contexto de crise econômica e de redução do papel do Estado nas economias capitalistas.

Na década de 1990 surgem propostas consolidadas de renda mínima com o Projeto de Lei nº 80 de 1991, do Senador Eduardo Suplicy, propondo a instituição do Programa de Garantia de Renda Mínima (PGRM). Desde então, o tema é recorrente na agenda pública brasileira, abrindo caminho para o surgimento de experiências pioneiras no ano de 1995 em municípios paulistas - Campinas, Ribeirão Preto, Santos - e em Brasília/DF. No âmbito do governo federal foram criados o Bolsa Escola em 1997, o Auxílio-Gás e o Cartão Alimentação (2001) durante o governo Fernando Henrique (1995-2002), e o Programa Bolsa Família em 2004, no governo Lula (2003-2010), programas esses classificados como programas de transferência de renda focalizado.

É a partir desse histórico de programas que se institui, em 2004, o Bolsa Família. Por meio da Lei n 10.836, de 9 de janeiro de 2004 (BRASIL, 2004), o Programa entra em cena e passa a ser o carro-chefe da assistência social brasileira. O número de famílias beneficiárias do Bolsa Família entre janeiro de 2004 e dezembro de 2014 saiu de 3,7 milhões para 14 milhões de famílias atendidas diretamente (Gráfico 1).

No primeiro ano já era possível observar a relevância que o PBF ganhava, pois entre janeiro e dezembro de 2004, no espaço de um ano, o número de famílias beneficiárias salta de 3,6 milhões para 6,5 milhões, uma variação positiva de $81,2 \%$, parte disso ocorreu muito em função da junção de programas de transferência de renda que já existiam. Com isso, o dispêndio mensal sai de 263 milhões de reais para 439 milhões em dezembro do mesmo ano, uma expansão de aporte mensal de 67\%. Entre janeiro de 2004 e dezembro de 2014, mais de 10 milhões de famílias foram incluídas no PBF (MINISTÉRIO..., 2020). Esse período também é marcado por intenso crescimento da economia brasileira, bem acima da média dos 13 anos que antecederam a criação do PBF, assim como a redução das taxas de desemprego, do crescimento do percentual da população ocupada e redução da pobreza.

A ampliação do investimento e a expansão do número de beneficiários fez o país se destacar internacionalmente no combate à pobreza, pois o Programa Bolsa Família atingiu a população vulnerável do país, atendendo até março de 2020, antes da crise da Covid-19, mais de 13 milhões de famílias, que corresponderam a mais 40 milhões de brasileiras e brasileiros consideradas pobres e extremamente pobres.

Conforme dados do Ministério da Cidadania (2020b), considerando o tamanho da população beneficiada, existem Estados que possuem quase $50 \%$ de sua população atendida, é o caso do Maranhão (44,44\%), por exemplo. No município de São Raimundo do Doca Bezerra (MA), 85,11\% da população é beneficiária, e em toda a região Nordeste $36,28 \%$ da população, o que só reforça a tese de que a pobreza se constitui em um problema grave e que não pode sair da agenda da política pública brasileira.

\footnotetext{
${ }^{5}$ Dados referentes a março de 2020.
} 
No período que vai de 2004 a 2013, conforme Gráfico 1, observa-se que tanto o BPC quanto o PBF apresentaram variação positiva com o avanço da política de transferência de renda. O Bolsa família sofre sua primeira inflexão em 2014, ano em que se registra a perda do benefício para 83 mil famílias. Já o BPC continua sua trajetória de expansão, com desaceleração, até 2018, e tem seu ponto de inflexão em 2019. Com base nos dados, não é demais afirmar que justamente no período de maior crise econômica e de redução do nível de ocupação, os governos federais adotaram políticas de retirada do cobertor social.

É justamente nesses momentos que a disputa pelo fundo público se torna mais acirrada e o capital passa querer a totalidade do fundo público. Com a chegada de Temer à presidência da república - maio de 2016 - até o presente momento, governo Bolsonaro, o capital avançou de forma avassaladora, sem precedentes, retirando direitos conquistados há mais de setenta anos, como os que constavam na Consolidação das Leis de Trabalho (CLT).

Gráfico 1 - Variação percentual do PBF, BPC e o nível de ocupação da força de trabalho - 20052020

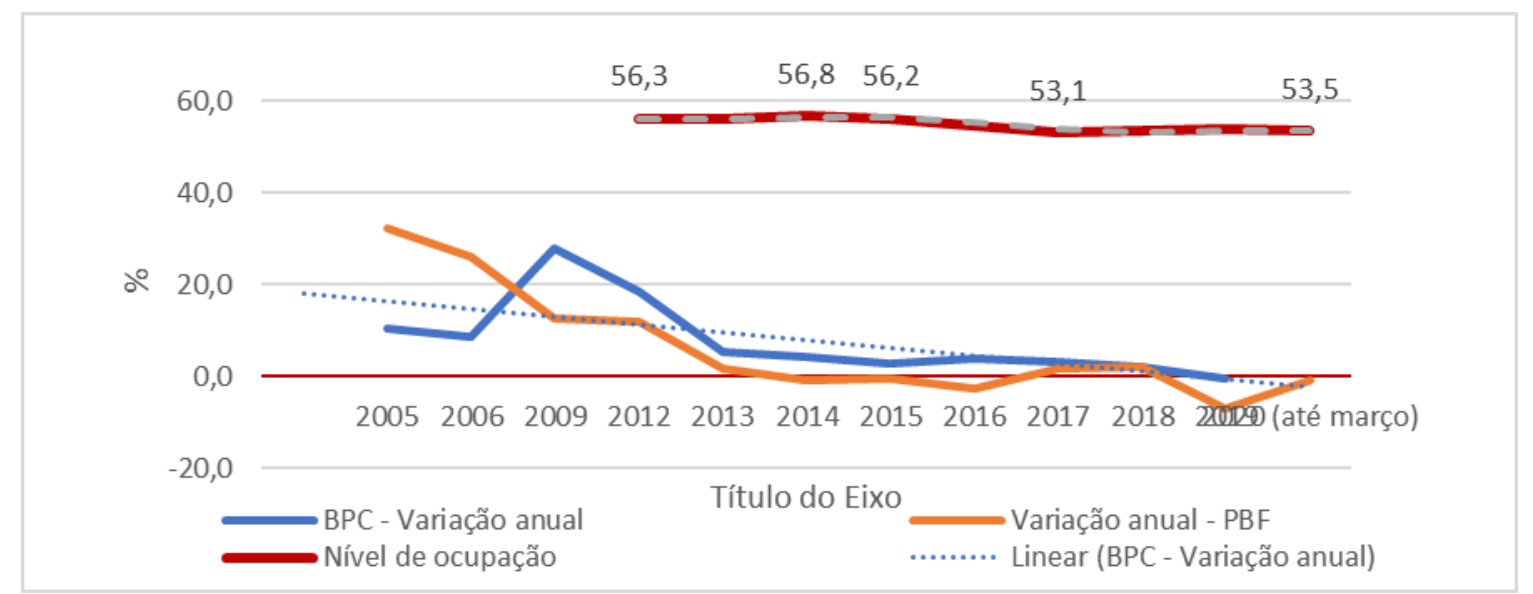

Fonte: Ministério da cidadania (2020a).

Entre 2016 e 2019, a benefício do capital, os presidentes da república e a maioria dos parlamentares no Congresso Nacional aprovaram a Emenda 95, que impôs à sociedade o teto dos gastos sociais; a contrarreforma trabalhista, que retira direito dos trabalhadores; e a contrarreforma da previdência. A todas essas políticas se atribuía, por parte do governo, a solução para os problemas brasileiros do desemprego, da pobreza e do déficit nas contas públicas. Mas, na verdade, o avanço do liberalismo econômico e a implantação das contrarreformas jogaram o país numa grande crise social e econômica a ponto de, em 2019, o país ter um PIB, em paridade de poder e compra, menor que o de 2014 (IPEADATA, 2020). O item seguinte tratará desse período em que se registram ataques às políticas de transferência de renda justamente no período que crescem a pobreza e o desemprego.

\section{Agenda neoliberal e o ataque às políticas de transferências de renda (2015-2020)}

Em janeiro de 2015, Dilma Rousseff é reeleita para o seu segundo mandato. Contudo, este durou apenas 16 meses, pois em 12 de maio de 2016, em função da abertura do processo de 
impeachment, a presidenta foi afastada do cargo. Durante os anos de 2015 e 2016, o contexto político estava bastante desfavorável para o governo, que perdia a base parlamentar e precisava enfrentar as famosas pautas-bombas aprovadas pelos parlamentares. Vale destacar que a presidenta muda a rota das políticas adotadas nos 11 anos anteriores (2004/2014), no que se refere às políticas de crescimento econômico com geração de ocupação e renda associadas à expansão das políticas de transferência de renda. Já em janeiro de 2015, a presidenta nomeia Joaquim Levy para ser o ministro da fazenda.

Levy já era conhecido pela defesa de políticas de austeridade fiscal rigorosas e, ao assumir o cargo, não fez diferente do que defendia. A partir de 2015, com a nova investida da agenda neoliberal, as políticas sociais estancam; o investimento estatal diminui; a economia cai 3,7\% (IBGE); as taxas de desemprego sobem e com ela expande-se a informalidade; volta a crescer a pobreza; e, em geral, o quadro social se deteriora. Mesmo com a mudança de ministro - Levy é substituído por Nelson Barbosa em dezembro de 2015 - a rota de descenso que entrou a economia brasileira não é debelada. Como era esperado, as políticas de ajuste fiscal levaram o país a sua mais intensa recessão dos últimos cem anos, com a economia caindo pelo segundo ano consecutivo, em 2016, mais 3,4\%. Com isso, a crise social se aprofunda. Apesar da queda do PIB, os lucros dos bancos seguem batendo recorde, muito em função do "bolsa juros".

É justamente em períodos de crise econômica que as políticas de renda são mais necessárias, tanto no sentido de mitigar os efeitos econômicos da crise na população mais vulnerável socialmente, quanto no sentido de se constituir em um fator que reverta a queda da economia. Contudo, não foi o que se viu no Brasil nesse período. Os governos optaram por políticas recessivas que priorizaram a agenda do capital financeiro (o rentismo), em detrimento das políticas sociais e de emprego até então adotadas.

Entre 2015 e 2016, justamente no período de uma das maiores crises da econômica brasileira, o governo federal reduziu os dispêndios com o PBF e excluiu quase meio milhão de famílias. Nos dois anos subsequentes - 2017 e 2018 - a tendência se manteve, apesar de uma fraca recuperação da cobertura do PBF (linha laranja, Gráfico 1).

Com a posse do novo presidente em 2019, a agenda ultraliberal é adotada e, com isso, ocorre maior ataque às políticas de transferência de renda desde a CF de 1988. Com pode ser verificado no Gráfico 2, entre janeiro de 2019 e março de 2020, o PBF excluiu mais de um milhão de famílias do benefício. Mesmo em 2020 com a pandemia da Covid-19 se espalhando pelo mundo e pelo Brasil, o governo federal manteve até março a política de exclusão. Para se ter uma ideia do tratamento dado pelo governo ao PBF, vale destacar que este chegou a remanejar para comunicação institucional do governo $\mathrm{R} \$ 83$ milhões de recursos do PBF que iriam para as famílias em vulnerabilidade social (RESENDE, 2020). 


\section{Gráfico 2 - Comportamento do número de beneficiários do PBF e BPC no governo} Bolsonaro - jan. de 2019 a março de 2020

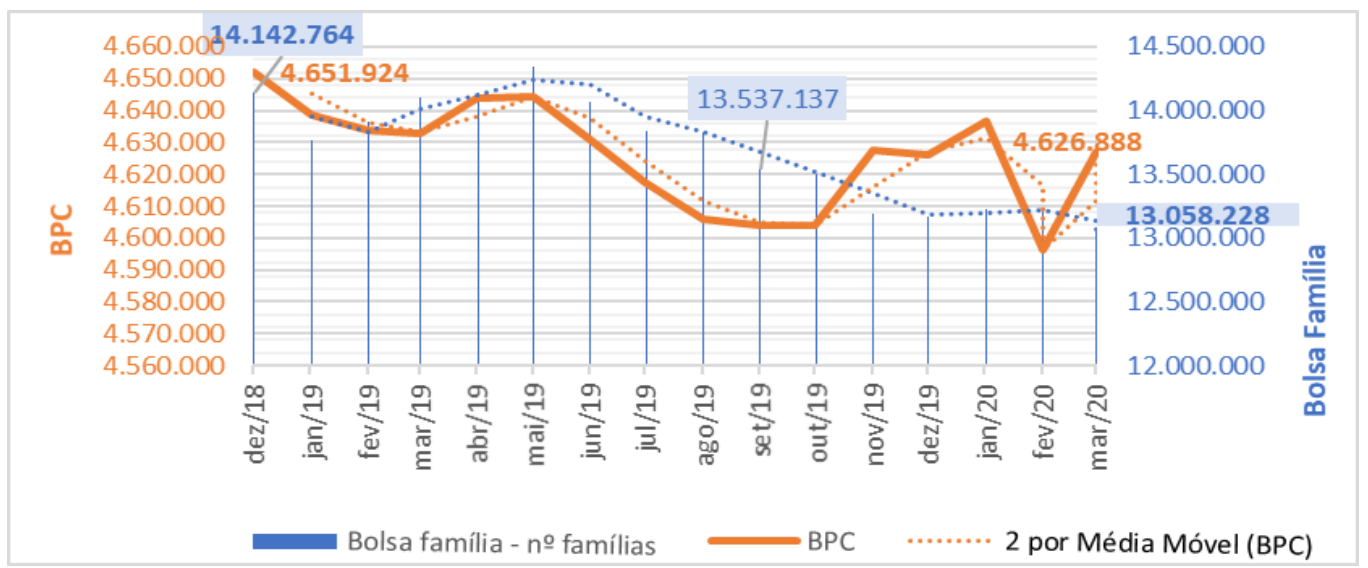

Fonte: Elaboração própria com base nos dados do Ministério da Cidadania (2020a).

Outro programa que também sofreu redução foi o Benefício de Prestação Continuada (BPC). Mesmo com o crescimento da população idosa e da pobreza no país, o BPC registrou uma queda de beneficiários de 0,6\% (Gráfico 2). O mesmo movimento pode ser observado até março de 2020, quando nos três primeiros meses o governo excluiu do PBF aproximadamente 112 mil famílias (MINISTÉRIO..., 2020). A política de ataque às políticas de transferência de renda só foram suspensas com o agravamento da crise sanitária, em abril de 2020.

Desse modo, como se observa no Gráfico 2, nos quinze primeiros meses do governo Bolsonaro, mais de um milhão de famílias foram excluídas do PBF. Mas não foi só, de modo geral, os programas de transferência de renda vinham apresentando redução no número de beneficiários e com tendência de que essa política iria se manter até o final do seu mandato. Contudo, a pandemia impôs mudanças dessa política.

\section{O advento do Auxílio Emergencial como instrumento de proteção social}

A crise desencadeada pela Covid-19 levou à necessidade fundamental de isolamento social progressivo a partir da segunda quinzena de março de 2020. No final desse mesmo mês, o Congresso Nacional pautou e aprovou uma lei que visava auxiliar a população mais vulnerável diante dos impactos da crise econômica que se desenvolvia. Inicialmente o governo queria implementar um auxílio de apenas $\mathrm{R} \$$ 200,00, mas os parlamentares apontaram para um mínimo de R \$ 500,00 e, pós-acordo com o líder do governo, foi aprovado um auxílio de $\mathrm{R} \$$ 600,00. Este foi estabelecido pela Lei n ${ }^{\mathrm{o}} 13.982$, de abril de 2020 (BRASIL, 2020a), e sofreu alterações conforme Lei no 13.998, de 14 de maio de 2020 (BRASIL, 2020b). Assim, a Lei $n^{\circ} 13.982$ e posteriores ajustes dados pela Lei no 13.998 disciplinam a concessão do benefício e amplia, temporariamente, a abrangência das políticas de renda mínima até então vigentes no país.

No Brasil, do ponto de vista da ação da política pública, pode-se considerar o Auxílio Emergencial uma política de proteção social, mesmo considerado como um auxílio de caráter extraordinário. Castro (2012, p.1018) destaca que esse tipo de política social tem o objetivo de “[...] reduzir 
e mitigar as contingências, necessidades e riscos a que qualquer indivíduo está exposto em uma sociedade de mercado, tal como o de não poder prover seu sustento e da família por meio do trabalho, seja por velhice, morte, doença ou desemprego[...]". Assim, de modo geral, todos os auxílios associados a aposentadorias, pensões, assistência social e seguro-desemprego congregam esse conjunto de ações. No entanto, para efeito de análise enfatizam-se aqui, além do Auxílio Emergencial, informações dos dois maiores programas que representam a significativa parte dos recursos da Assistência Social, bem como o maior número de beneficiários, no caso o PBF e o BPC, já referidos em seções anteriores. No Quadro 1 a seguir são apresentadas sinteticamente as características principais dos benefícios referidos.

Quadro 1 - Comparativo entre Programa Bolsa Família (PBF), Benefício de Prestação Continuada (BPC) e Auxílio Emergencial (AE)

\begin{tabular}{|c|c|c|c|}
\hline $\begin{array}{l}\text { Programas/ } \\
\text { características }\end{array}$ & BPC & PBF & AE - Lei $n^{\circ} 13.982$ de $2 / 4 / 20$ \\
\hline $\begin{array}{l}\text { Prazo do } \\
\text { Programa }\end{array}$ & Indeterminado & $\begin{array}{l}\text { Variável: dependerá do perfil dos } \\
\text { integrantes da família. }\end{array}$ & 5 meses $(3+2)$ \\
\hline $\begin{array}{l}\text { Idade mínima do } \\
\text { beneficiário }\end{array}$ & $\begin{array}{c}\text { Idoso acima de } 65 \text { anos } \\
\text { ou pessoa com } \\
\text { deficiência }\end{array}$ & $\begin{array}{l}\text { Destinado às famílias em situação } \\
\text { de pobreza ou extrema pobreza. }\end{array}$ & $\begin{array}{c}18 \text { anos, salvo o caso de mães } \\
\text { adolescentes. }\end{array}$ \\
\hline Renda por pessoa & $\begin{array}{l}\text { Menor ou igual a } 1 / 4 \text { do } \\
\text { salário mínimo }\end{array}$ & $\begin{array}{c}\text { Famílias em situação de pobreza } \\
\text { com renda per capita de até R\$ } \\
178,00^{* *} \text { e extrema pobreza até RS } \\
89,00 * *\end{array}$ & $\begin{array}{l}\text { Menor ou igual 1/2 salário mínimo } \\
\text { ou renda familiar mensal total seja } \\
\text { de até } 3 \text { (três) salários mínimos; } \\
\text { não ter recebido acima de R\$ } \\
\quad 28.559,70\end{array}$ \\
\hline Limite por família & $\begin{array}{l}\text { Pode cobrir mais de uma } \\
\text { pessoa da família se } \\
\text { atendidos os requisitos } \\
\text { exigidos. }\end{array}$ & $\begin{array}{l}\text { Variável a depender da composição } \\
\text { da família. }\end{array}$ & $\begin{array}{l}\text { Limite de duas pessoas por família } \\
\text { No caso da mulher provedora de } \\
\text { família monoparental, esta receberá } \\
2 \text { (duas) cotas do auxílio. }\end{array}$ \\
\hline Valor do benefício & 1 salário mínimo & $\begin{array}{l}\text { Variável com valor médio de } \\
\mathrm{R} \$ 185,00\end{array}$ & $\mathrm{R} \$ 600,00$ até $\mathrm{R} \$ 1.200,00$ \\
\hline Abrangência & $4.748 .984^{*}$ & $13.170 .607^{*}$ & $65.000 .000 * * *$ \\
\hline $\begin{array}{l}\text { Recursos } \\
\text { financeiros }\end{array}$ & $\mathrm{R} \$ 19.275 .490 .190,70^{*}$ & $\mathrm{R} \$ 31.159 .235 .696,00^{*}$ & $\begin{array}{c}\mathrm{R} \$ 116 \text { bilhões creditados até } \\
03 / 07 / 20 \text {. Total previsto a ser } \\
\text { pago } \\
\mathrm{R} \$ 250 \text { bilhões } \\
\end{array}$ \\
\hline \multicolumn{4}{|c|}{$\begin{array}{l}\text { Fonte: MDS (2000), Decretos 5.209/2004 (BRASIL, 2004), Decreto 9.396/2018 (BRASIL, 2018), CEF (2020) } \\
* \quad \text { Valor anual referente a } 2019 . \\
\text { ** Valor definido pelo governo federal pelo decreto 5.209/2004 e atualizado pelo decreto 9396, de } 30 \text { maio de } 2018 \text {. } \\
\text { *** Nesses números são computados } 19,2 \text { milhões de beneficiários que boa parte deles antes se encontravam no Programa Bolsa } \\
\quad \text { Família. Os dados são referentes à situacão em 03/07/2020. }\end{array}$} \\
\hline
\end{tabular}

Após o início da execução do auxílio emergencial pelo governo federal - com a operacionalização a cargo do Ministério da Cidadania, do banco estatal Caixa Econômica Federal e Dataprev - foi possível observar o alto número de brasileiros que recorreram a esse auxílio financeiro. Até 03 de julho, registravam-se mais de 109 milhões de brasileiros cadastrados e 65,1 milhões elegíveis, aptos a receberem o benefício. Dos cadastrados, 42,2 milhões de pessoas foram consideradas inelegíveis (Tabela 1). De acordo com os dados, pouco mais da metade da população brasileira recorreu a esse auxílio e quase 1/3 (um terço) da população foi considerada elegível. Merece destaque na lei que aprova o AE a linha de corte por renda considerar $1 / 2$ (meio) salário mínimo e não mais 1/4 do salário ou valor R $\$ 178,00$ como definidor da linha de pobreza do PBF. 
Destacados alguns avanços do AE, surge também a pergunta: por que mais de 42,2 milhões de pretendentes foram considerados inelegíveis? Bem, a resposta oficial é de que essas pessoas não preenchem os requisitos estabelecidos na Lei $n^{\circ}$ 13.982/2020. Contudo, vale destacar, além das incongruências verificadas concretamente ao se negar o auxílio por parte dos operadores do programa, o que levou a milhões de pedidos de reanálise, há também restrições legais que vieram em forma de requisitos e outras operacionais que impedem o acesso de muitos trabalhadores ao auxílio.

Tabela 1 - Números do Auxílio Emergencial, em milhões de pessoas e valores pagos (R\$ bilhões)

\begin{tabular}{l|c|c|c|c|c}
\hline $\begin{array}{c}\text { Auxílio Emergencial em } \\
\text { milhões de pessoas }\end{array}$ & $\begin{array}{c}\text { Bolsa } \\
\text { Família }\end{array}$ & CadÚnico & App/site & $\begin{array}{c}\text { Total de } \\
\text { pessoas }\end{array}$ & $\begin{array}{c}\text { Total pago em } \\
\text { bilhões de } \\
\text { Reais até } \\
\mathbf{3 / 7 / 2 0}\end{array}$ \\
\hline Cadastrados & 19,9 & 32,1 & 57,1 & 109,1 & \\
\hline Processados & 19,9 & 32,1 & 55,7 & 107,1 & \\
\hline Elegíveis & $\mathbf{1 9 , 2}$ & $\mathbf{1 0 , 5}$ & $\mathbf{3 5 , 5}$ & $\mathbf{6 5 , 1}$ & \\
\hline Inelegíveis & 0,7 & 21,6 & 20,2 & 42,2 & \\
\hline $\begin{array}{l}\text { Valor pago em bilhões de } \\
\mathbf{R} \$\end{array}$ & $\mathrm{R} \$ 45,5$ & $\mathrm{R} \$ 19,5$ & $\mathrm{R} \$ 51,8$ & & $\mathbf{R} \mathbf{\$ 1 1 6 , 8}$ \\
\hline $1^{\circ}$ análise & & & 1,4 & & \\
\hline Reanálise & & & 0,8 & & \\
\hline
\end{tabular}

Fonte: CEF (2020).

Com relação à questão operacional, atribui-se a elementos objetivos e subjetivos na avaliação do cadastro via informações cruzadas desatualizadas que impedem milhões de brasileiros e brasileiras acessarem o recurso. Por exemplo, o sistema acusa o registro de trabalho formal para pessoas que não se encontram mais nessa condição. Essa falha decorre do fato de o antigo empregador não ter dado baixa na carteira de trabalho ou o governo não ter buscado bases de dados que permitissem identificar tal registro. Há casos em que o endereço domiciliar desatualizado faz o sistema cruzar informações não mais condizentes com a realidade do solicitante do recurso, entre tantos outros problemas identificados. Tem ainda o requisito legal que só permite duas pessoas por família, quando se sabe que numa família de baixa renda há mais de duas pessoas na informalidade, algo muito comum. Nesse sentido, o PBF e o BPC se apresentam com maior aderência à realidade brasileira.

Esses dados da Tabela 1 explicitam a realidade do mercado de trabalho brasileiro e a situação da população, especialmente dos desocupados e dos ocupados informais, ao mostrar a ausência de proteção social para milhões de brasileiros. Esses trabalhadores não podem contar com o seguro-desemprego, com FGTS ou qualquer outro benefício de proteção ao trabalhador, assim restou como alternativa recorrer ao Auxílio Emergencial.

O agravamento da crise econômica chama atenção à necessidade de expansão do programa de transferência de renda, pois a desocupação, associada à crise sanitária, teve e tem fortes implicações nas condições de vida dos trabalhadores(as) brasileiros(as). O mercado já demonstrou sua incapacidade de reação diante da crise. Os defensores do mercado mostram de forma mais explícita suas contradições ao 
pedir e aguardar o socorro do Estado. Nessa perspectiva, os mitos do mercado autorregulado, das políticas de austeridade fiscal e do estado mínimo são desfeitos pela força dos acontecimentos, pelo poder de verdade da realidade, obrigando os paladinos do Estado mínimo e do mercado autorregulado a aplaudir o socorro de mais de um trilhão de reais ao sistema financeiro e a solicitar mais intervenção na economia e, inclusive, alguns deles já reconhecem os problemas gerados pela lei do teto dos gastos sociais. Contudo, não se pode deixar enganar! Passada a crise, eles retomaram o discurso de austeridade fiscal como política primeira a ser adotada pelo Estado.

No que tange à política de transferência de renda, cabe destacar que tanto liberais quanto progressistas têm defendido ações emergenciais de combate à Covid-19. Contudo, convém destacar que a concordância na defesa começa a diferenciar liberais e progressistas, à medida que se passa a discutir a duração, o alcance e o valor de benefícios dessa natureza. Milton Friedman, por exemplo, em seu livro publicado em 1962 "Capitalismo e Liberdade”, defendia a existência de uma renda mínima para atacar o problema da pobreza, a ser estruturada em forma de um imposto de renda negativo ${ }^{6}$, sem distorcer o mercado ou afetar o seu funcionamento em direção à substituição de boa parte das prestações sociais existentes. Assim, estas se davam com a retirada do Estado das políticas sociais, dos serviços públicos e das intervenções no mercado. Por outro lado, os progressistas defendem políticas de transferência de renda associada a reformas estruturais (agrária, tributária, urbana) e ao fortalecimento dos serviços públicos. Isto é, mais Estado e não menos Estado.

\section{A contribuição da transferência de renda para intervir nos velhos problemas descortinados}

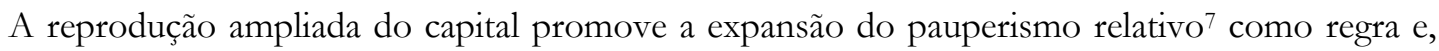
muitas vezes, amplia a pobreza absoluta como tendência que quase sempre se confirma, a não ser nos períodos em que o Estado interfere nas leis econômicas tendenciais inerentes ao processo de acumulação de capital.

Sabe-se que os programas de transferência de renda são limitados, uma vez que não são capazes de gerar transformações estruturais, pois atuam apenas no fluxo de renda ao promover sua redistribuição. Assim, quando se adota apenas essa política dissociada de mudanças estruturais, a sociedade permanecerá perpetuando as desigualdades, uma vez que o monopólio dos meios de produção e, por conseguinte, do conhecimento, do dinheiro, da riqueza e do poder político continuarão concentrados nas mãos dos capitalistas.

Nesse sistema, a acumulação ampliada de capital se impõe e, para tanto, os donos do dinheiro, a burguesia, farão uso de todos os meios para concentrar e centralizar a riqueza. Assim, os elementos geradores da desigualdade e da superexploração serão recolocados. As crises, inclusive, são momentos oportunos para os capitalistas intensificarem o processo de concentração e, principalmente, a centralização

\footnotetext{
${ }^{6} \mathrm{O}$ caminho seria a adoção de um imposto de renda negativo que consideraria um limite de renda familiar (uma linha de pobreza) que estabelece um patamar sob o qual paga-se imposto, se a renda é maior que a linha de pobreza e, ao contrário, se a renda for menor uma renda complementar é concedida.

${ }^{7}$ Marx, nos Manuscritos Econômicos-Filosóficos (2002), observa que o pauperismo (pobreza) relativo tendia a crescer ainda que a pobreza absoluta caísse.
} 
de capital. É comum nesses momentos a constatação do aumento das desigualdades e da pobreza. A política de transferência de renda atuará aí como uma contratendência ao maior empobrecimento dos trabalhadores. Desse modo, não se deve iludir, as políticas de transferência de renda devem vir acompanhadas de uma agenda mais ampla.

Muito embora se constatem limitações ao alcance isolado dessa política, vale destacar dois aspectos positivos acerca da adoção das políticas de transferência de renda: primeiro, porque se faz justiça social ao transferir parcela da renda gerada pelos trabalhadores e apropriada pelo Estado, via impostos, voltar para os trabalhadores socialmente mais vulneráveis, tentando minimamente assegurar "a cada um de acordo com suas necessidades"; segundo, porque essa renda distribuída às famílias além de fazer justiça (nos limites da sociedade do capital) também atuará no sentido de impulsionar a economia, uma vez que a propensão marginal a consumir dos beneficiários é de 100\%. Isto é, esse dinheiro na sua integralidade retornará para a economia na forma de consumo.

Desse modo, em momentos de crise como o atual, essa política pode reduzir o tamanho da queda da economia, diminuir a força da tendência do capital em ampliar a concentração e, ao mesmo tempo, pode ser instrumento de recuperação econômica. Segundo Keynes (1983), quanto menor for a renda maior será a propensão marginal a consumir. Assim, considerando o multiplicador dos gastos do governo de 1.5, por exemplo, nas condições atuais, o investimento de $\mathrm{R} \$ 250$ bilhões no Auxílio Emergencial tende a gerar uma renda de $\mathrm{R} \$ 375$ bilhões ao longo dos cinco meses. Parte desse recurso volta para o governo em forma de tributos. Como a carga tributária no Brasil está em torno dos 33\% (esferas: federal, estadual e municipal), espera-se uma arrecadação em torno de 125 bilhões. Logo, o custo do programa tende a ficar em torno de 125 bilhões (sem considerar vazamentos). Vale destacar que os gastos do governo em nada se parecem com os gastos das famílias. Ao gastar tudo mais constante, o governo amplia sua base arrecadatória, além de outros efeitos positivos; enquanto o gasto da família finda no consumo.

Nesse sentido, a política de transferência de renda, além de ser um instrumento importante no combate à pobreza no curto prazo, também serve de freio ao ímpeto do sistema de intensificar a pobreza e as desigualdades, atua no estímulo a atividade econômica, na geração de emprego, no aumento da renda nacional, e, por conseguinte na elevação da arrecadação. Desse modo, há várias razões que justificam a expansão da política de transferência de renda que não deve ser só emergencial, como recentemente aprovado e implementado no Brasil, mas deve abrir caminho em direção a uma política permanente de Estado.

Freire et al (2020) apresentam um estudo sobre os impactos econômicos da Renda Emergencial tal qual foi aprovada pelo Congresso Nacional (por três meses). De acordo com os resultados, constatam-se efeitos positivos na renda dos beneficiários, mas também gera um impacto positivo para a economia, no que tange aos impactos setoriais, no PIB como um todo e na arrecadação de impostos. O estudo ainda apresenta um cenário no qual essa renda emergencial é estendida até o final do ano de 2020, o que também resulta em números positivos para a economia. No que se refere aos impactos no PIB, o estudo mostra que a garantia do benefício pelos três meses irá gerar um crescimento deste na ordem de $0,44 \%$. 
Ou seja, num contexto de queda do PIB já prevista por diversos órgãos e instituições, o Auxílio Emergencial constitui um elemento que mitiga parte da queda da economia. No segundo cenário, considerando que a renda básica é estendida "[...] o aumento imediato do PIB chegaria a 0,55\% com a manutenção do auxílio até o fím do ano e 0,31\% de impacto permanente até 2021" (FREIRE et al. 2020, p.10).

Nesse sentido, não se pode negar que existem argumentos técnicos e teóricos que reforçam a pertinência desse instrumento. O que não há é vontade política para mudar os rumos do país em direção a uma nação que promova mais igualdade social. Nessa linha de proposições uma série de estudos e pesquisas tenta apontar caminhos que possam viabilizar a concretização de políticas mais permanentes como um programa de renda mínima.

A questão que surge é: como financiar uma política de transferência de renda com raio maior de abrangência do que as praticadas até março de 2020. Bem, há vários estudos que apontam caminhos e fontes de financiamento. Podem-se considerar dois caminhos convergentes: o primeiro implica mudanças na estrutura tributária que tornem os impostos progressivos, fazendo com que quem ganha mais pague mais impostos, especialmente os ricos; segundo, redução dos gastos tributários (desonerações, isenções, etc.).

Em carta aberta, produzida por um grupo de entidades especializadas em estudos tributários, intitulada "Tributar os ricos para enfrentar a crise" (AFD/ANFIP/FENAFISCO/IJF, 2020), são propostas a criação de alguns impostos/contribuições e retirada de algumas isenções que podem gerar de arrecadação 270 bilhões de reais ao ano. Aqui serão destacadas apenas três propostas: $1^{\circ}$ ) A Contribuição Social sobre Altas rendas das Pessoas Físicas (CSPF), com alíquota de 20\%, incidência sobre rendimentos de qualquer natureza que ultrapassem 80 mil reais por mês. A CSPF alcançaria apenas 194 mil pessoas, as quais se encontram entre os 0,01\% mais ricos. Estima-se que poderia arrecadar 72 bilhões de reais com CSPF; $2^{\circ}$ ) O imposto sobre grandes fortunas (IGF) com três alíquotas sobre o patrimônio que exceder 20 milhões de reais pode permitir arrecadar 40 bilhões de reais; e, $3^{\circ}$ ) uma alíquota de 25\% sobre lucros e dividendos remetidos ao exterior, no caso de paraíso fiscal, uma alíquota de 50\% pode gerar uma arrecadação adicional de 28 bilhões de reais.

O segundo aspecto que deve ser atacado são os gastos tributários - subsídios, isenções, desonerações e benefícios tributários - estes, segundo Ministério da Economia representaram uma perda de receita da União de $\mathrm{R} \$ 362,9$ bilhões, o equivalente a 5,5\% do PIB de 2017 (ME, 2020). A perda de receita com esses subsídios em 2011 foi de 152 bilhões; em 2012 R \$181,7 bilhões; em 2013 igual R\$223,2 bilhões; em 2014, R\$256,2; e em 2015 R\$ 270,1 bilhões (PELLEGRINI, 2018). Assim, acredita-se que há espaço fiscal para o financiamento de uma política de transferência de renda mais robusta que atenda de fato a população em vulnerabilidade social e combata a pobreza.

\section{Por fim, um olhar para fora}

Referindo-se ao contexto internacional, as experiências lançadas em prol da garantia de renda são inúmeras e só reforçam a necessidade desse debate. Entre as diversas iniciativas de programas de 
transferências de renda que passaram a valer durante a pandemia, destaca-se o exemplo espanhol. Em 29 de maio foi aprovada na Espanha a Renda Mínima Vital, inicialmente definida para 12 meses, é um programa de renda que irá atender famílias em situação de vulnerabilidade econômica. O valor dependerá da composição familiar do domićlio, mas poderá variar de €462,00 ( $\mathrm{R} \$ 2.786,00)$ a $€ 1.015,00$ $(\mathrm{R} \$ 6.121,00)^{8}$. A ideia do governo é atingir na primeira etapa 75.000 domicílios e com o tempo chegar até 850.000. O titular do benefício deve ter entre 23 e 65 anos. Cabe ressaltar que a Espanha já possui outros tipos de auxílio, mas que variam entre as regiões (LIMA, 2020; REQUISITOS..., 2020).

Esse programa é o primeiro em escala nacional e que irá beneficiar todos que comprovem vulnerabilidade econômica, independentemente de ter emprego ou não. $\mathrm{O}$ custo anual estimado do programa é de 3 bilhões de Euros (LIMA, 2020). Considerando as três características de uma renda básica universal (universal, incondicional e individual), podemos dizer que ela atende apenas a segunda característica, pois não há nenhuma condicionalidade prevista a ser cumprida. Ela não é universal, pois atende apenas aos mais vulneráveis e não necessariamente é individual, pois para a definição da renda se considera a composição da unidade domiciliar. No entanto, é preciso destacar que é uma iniciativa de fundamental importância nesse contexto de pauperização da população mundial já presente e crescente a partir de agora.

Na América Latina, a pandemia da Covid-19 também produziu efeitos deletérios na saúde, no crescimento econômico e no desenvolvimento social dos países da região. E as populações mais vulneráveis são o grupo que mais sofre. Segundo estudos da CEPAL (2020), todas as projeções indicam aumento da pobreza e extrema pobreza nos países da América Latina, com destaque para o aumento da pobreza em geral para México, Argentina e Brasil, as três maiores economias da região.

De acordo com o informe da CEPAL (2020), até 24 de abril, um conjunto de 29 países adotaram alguma medida de proteção social ${ }^{9}$, entre elas se destacam: entrega de alimentos e medicamentos $(33 \%$ das medidas); aumento das transferências monetárias (13\% das medidas); aumento da cobertura da população para transferências de renda existentes (4\%); suspensão de pagamentos de serviços básicos $(19 \%$ das medidas); e criação de transferências monetárias (27\% das medidas). Destaca-se a última medida que foi implementada em 23 países da região, o que demonstra o aprofundamento do grave quadro de vulnerabilidades social.

A Cepal (2020) ressalta que uma das inovações da proteção social na região, neste momento, foi a implementação de transferências monetárias para trabalhadores informais, na perspectiva de mitigar a queda da renda desse segmento. De fato, essa é uma constatação importante, pois até então, na América Latina, as políticas focalizadas de combate à pobreza direcionavam programas de transferência de renda a públicos-alvo diferentes associados à composição familiar e à renda familiar e não necessariamente à ocupação, o que sinaliza uma questão relevante, pois a precariedade da renda de uma significativa parcela

\footnotetext{
${ }^{8}$ Com base na cotação do dólar de 10 de julho de 2020.

9 Cabe destacar que são integrantes da CEPAL 33 países da América Latina e Caribe, além de países membros externos, totalizando 46 Estados-membros.
} 
da população já se constituía em problemática para os especialistas, mas infelizmente não se fazia presente no âmbito da agenda da política pública de modo mais amplo.

\section{Considerações finais}

A questão da condição de sobrevivência diante da situação de pobreza de parte da população em diversas formações sociais está presente na história da humanidade. Neste estudo, constatou-se que as políticas de combate à pobreza adotadas até hoje não foram implementadas no sentido de erradicar a pobreza, no máximo, tentou-se apenas controlar/administrar a pobreza em bases aceitáveis, isso quando muito.

Se é possível afirmar que em outros modos de produção as forças produtivas eram atrasadas e havia escassez de alimentos e de produtos em geral que permitissem atender a todos, na sociedade capitalista essa afirmativa é falsa. O avanço das forças produtivas na sociedade contemporânea permite elevar o padrão de vida das pessoas, especialmente daqueles que estão em situação de vulnerabilidade social. Já há condições para erradicar a fome, a pobreza e várias doenças que atingem principalmente a população pobre.

No caso brasileiro, nunca se buscou alterar as estruturas que levam as pessoas a permanecerem em situação de pobreza. Mesmo quando se olha para os importantes avanços nas políticas de transferência de renda no período 2004-2014, com destaque para o PBF e BPC, constata-se que as linhas de pobrezas estabelecidas não são condizentes com a nossa realidade e sequer se aproximam do valor estabelecido pelo Banco Mundial, que considera pobre a pessoa com renda mensal inferior a $\mathrm{R} \$ 422,00$, que hoje corresponde a $44 \%$ do salário mínimo, ou US\$ 5,50 por dia. O PBF estabelece a linha de corte em R \$ 178,00, e o BPC em $1 / 4$ do salário mínimo, o equivalente a $\mathrm{R} \$ 261,25$.

Ainda assim, esses programas sofreram ataques entre 2015 até março de 2020 . O maior ataque ocorreu com a exclusão de mais de um milhão de famílias do PBF nos primeiros 15 meses do governo Bolsonaro. Já o BPC, a primeira tentativa de ataque veio com a proposta de contrarreforma da previdência, quando se tentou reduzir o valor do benefício de 1 (um) para $1 / 2$ (meio) salário mínimo. Este último também teve o número de beneficiários reduzido em torno de 25 mil pessoas no período supracitado. Desse modo, a proteção social sofreu duros ataques ao longo dos primeiros quinze meses do governo Bolsonaro. A crise sanitária causada pela Covid-19, na cambaleante economia brasileira, foi o fator que levou a uma inflexão dos ataques, ainda que o governo federal menosprezasse os efeitos da pandemia na saúde e na economia.

Com o agravamento da crise, foi criado o Auxílio Emergencial, importante instrumento de política social para combater os efeitos da crise na população em situação de vulnerabilidade social. A extensão da sua cobertura é um dado positivo quando se olha para trás, por exemplo, mas quando se olha para o presente, diante da profundidade da crise social, o auxílio que alcançou 65 milhões de brasileiros se revelou pequeno diante do número de pedidos. Mais de 40 milhões de pessoas que solicitaram ficaram de fora. 
A criação de auxílio monetário para a população socialmente vulnerável não foi uma exclusividade brasileira. Segundo a CEPAL, só na América latina 23 países adotaram algum programa novo de transferência de renda. Das experiências europeias, foi destacado ao longo desse artigo o caso da Espanha que criou a Renda Mínima Vital com tempo de duração inicial de 12 meses, o valor do benefício poderá variar de $€ 462,00(\mathrm{R} \$ 2.786,00)$ a $€ 1.015,00(\mathrm{R} \$ 6.121,00)$. Vale ressaltar que a Espanha manteve os outros programas de transferência de renda.

Como horizonte de ação política para o Brasil, espera-se que a sociedade se mobilize e o congresso aprove a manutenção do AE até a implementação de um programa de renda mínima de caráter permanente, capaz de combater a pobreza e reduzir as desigualdades pari passu ao avanço de reformas como: 1) tributária, com as inclusões do IGF e do CSPF, aplicação de imposto progressivo; 2) reforma urbana; 3) fortalecimento e estatização do transporte público; 4) linhas de crédito específicas para os pequenos negócios (produção, comércio e serviços), com apoio institucional para a reorganização dessas atividades em cooperativas, entre outras medidas.

\section{Referências}

AFD/ANFIP/FENAFISCO/IJF, Auditores Fiscais pela Democracia/Associação Nacional dos Auditores Fiscais, da Receita Federal do Brasil/Federação Nacional do Fisco Estadual e Distrital/Instituto Justiça Fiscal. Tributar os ricos para enfrentar a crise. Mar.2020. Disponível em:

$<$ http://plataformapoliticasocial.com.br/wpcontent/uploads/2020/03/carta com link para assinar.pdf $>$

BRASIL. Lei 10.836, de 4 de janeiro de 2004. Cria o Programa Bolsa Família e dá outras providências. Brasília, D.F. Diário Oficial da União, 12 jan.2004. Disponível em: http://www.planalto.gov.br/ccivil_03/Ato2004-2006/2004/Lei/L10.836.htm

BRASIL. Lei 13.982, de 2 de abril de 2020. Altera a Lei no 8.742, de 7 de dezembro de 1993, [...] e estabelece medidas excepcionais de proteção social [...] decorrente do coronavírus (Covid-19) [...], a que se refere a Lei no 13.979, de 6 de fevereiro de 2020. Diário Oficial da União, edição extra A. Brasília, D.F., 2 abril. 2020a. Disponível em: http://www.planalto.gov.br/ccivil 03/ ato20192022/2020/lei/113982.htm

BRASIL. Lei 13.998, de 14 de maio de 2020. Promove mudanças no auxílio emergencial instituído pela Lei $\mathrm{n}^{\circ}$ 13.982, de 2 de abril de 2020; e dá outras providências. Diário Oficial da União. Brasília, D.F., 15 mai. 2020b. Disponível em: http://www.planalto.gov.br/ccivil 03/ato2019-2022/2020/lei/L13998.htm

CASTRO, Jorge Abrahão de. Política Social e desenvolvimento no Brasil. Economia e Sociedade, Campinas, v.21, Número Especial, p.1011-1042, dez.2012.

CEF, Caixa Econômica Federal. Ações para mitigação de impacto Covid-19. 2020. Disponível em: $<$ https://caixanoticias.caixa.gov.br/wpcontent/uploads/2020/07/Auxilio_Emergencial_03_JUL_PARTE-1.pdf> Acesso em: 05/07/2020

CEPAL, Comissão Econômica da América Latina. E1 desafío social en tiempos del Covid-19. Santiago de Chile, Informe Especial n.3, 12 maio.2020. Disponível em:

< $\underline{\text { https://www.cepal.org/es/publicaciones/45527-desafio-social-tiempos-covid-19> }}$ 
COSTA, Andréa Braz da; SOARES, Marcos Antonio Tavares. Entenda porque o Auxílio Emergencial deveria ser uma política permanente no Brasil. Avoador, Vitória da Conquista, BA, 18 abril.2020.

Disponível em: https://avoador.com.br/opiniao/entenda-porque-o-auxilio-emergencial-deveria-ser-umapolitica-permanente-no-brasil//

FREIRE, Débora; DOMINGUES, Edson; MAGALHÃES, Aline; SIMONATO, Tiago; MIYAGIMA, Diego. Renda Básica Emergencial: uma resposta suficiente para os impactos econômicos da pandemia da Covid-19 no Brasil? Nota Técnica. Belo Horizonte, MG: NEMEA/CEDEPLAR/UFMG, 20.mai.2020. Disponível em: $<$ https://www.cedeplar.ufmg.br/noticias/1245-nota-tecnica-renda-basica-emergencialuma-resposta-suficiente-para-os-impactos-economicos-da-pandemia-da-covid-19-no-brasil> Acesso em: $25 / 05 / 2020$.

FRIEDMAN, Milton. Capitalismo e Liberdade. 3.ed. São Paulo: Nova Cultural, 1988. (Coleção Os Economistas).

IBGE, Instituto Brasileiro de Geografia e Estatística. Síntese de Indicadores Sociais: uma análise das condições de vida da população brasileira. Brasília, D.F.:IBGE, 2019.

IBGE, Instituto Brasileiro de Geografia e Estatística. Pesquisa Nacional por Amostra de Domicílios Contínua Trimestral - PNADC. 2020. Disponível em: < https://sidra.ibge.gov.br/tabela/4093>

IPEADATA. Brasil - Produto interno bruto (PIB): conceito de paridade do poder de compra (PPC). Frequência: Anual de 1980 até 2018. Brasília, D.F., 2020. Disponível em:

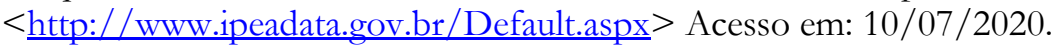

KEYNES, John Maynard. A teoria geral do emprego, do juro e da moeda; Inflação e deflação. São Paulo: Abril Cultural, 1983.

LIMA, Juliana Domingos de. Espanha: como a pandemia acelerou um programa de renda básica. Nexo Jornal, São Paulo, 11 Jul.2020. Disponivel em:

https://www.nexojornal.com.br/expresso/2020/07/11/Espanha-como-a-pandemia-acelerou-umprograma-de-renda-básica

Marx, K. Manuscritos Econômicos-Filosóficos. São Paulo: Martin Claret, 2002.

MINISTÉRIO DA CIDADANIA. RI social: relatório de programas e ações. 2020b. Disponível em: https://aplicacoes.mds.gov.br/sagi/ri/relatorios/mds/

MINISTÉRIO DA CIDADANIA. CECAD 2.O: benefícios do Programa Bolsa Família e do Benefício de Prestação Continuada. 2020a. Disponível em:

$<$ https://aplicacoes.mds.gov.br/sagi/cecad20/agregado/resumovariavelCecad.php?uf ibge=6\&nome est $\underline{\text { ado }=\& \mathrm{id}=79}>$

ME, Ministério da Economia. Subsídios da União caem em 2018 pelo terceiro ano consecutivo. 22 abr.2020. Disponível em: $<$ https://www.gov.br/economia/pt-

$\mathrm{br} /$ assuntos/noticias/2019/04/subsidios-da-uniao-caem-em-2018-pelo-terceiro-anoconsecutivo $>$

PELLEGRINI, Josué Alfredo. Gastos (benefícios) tributários. Brasília, D.F.: Instituto Fiscal Independente, 2018. (Nota Técnica n¹7). Disponível em: < $\underline{\text { https://www12.senado.leg.br/ifi/pdf/nota- }}$ tecnica-no-17-gastos-beneficios-tributarios-jun-2018/view $>$

REQUISITOS para solicitar el ingreso mínimo vital a través de la Seguridad Social. El Confidencial, Espanha, 23 Jun.2020. Disponível: https://www.elconfidencial.com/economia/2020-06-23/ingresominimo-vital-requisitos-seguridad-social_2552379/ 
RESENDE, Thiago. Governo tira dinheiro do Bolsa Família no Nordeste para bancar publicidade oficial. Folha de São Paulo, São Paulo, 4 Jun.2020. https://www1.folha.uol.com.br/mercado/2020/06/governo-tira-dinheiro-do-bolsa-familia-no-nordestepara-bancar-publicidade-oficial.shtml

SIDRA/IBGE. Sistema IBGE de Recuperação Automática. Taxa de desoupação. Disponível em: $<$ https://sidra.ibge.gov.br/tabela/6381\#resultado> Acesso em: 10/07/2020.

SUPLICY, Eduardo Matarazzo. Renda de cidadania: a saída é pela porta. São Paulo: Fundação Perseu Abramo; Cortez, 2002. 